\title{
Inclusion in Paralympic Sports from 2010 to 2021: A Systematic Review
}

\author{
Angela Magnanini* , Giulio Morelli \\ Department of Sport, Health and Human Sciences, University of Rome Foro Italico, Rome, Italy.
}

\begin{abstract}
How to cite this paper: Angela Magnanini, Giulio Morelli. (2021). Inclusion in Paralympic Sports from 2010 to 2021: A Systematic Review. The Educational Review, USA, 5(9), 316-327.

DOI: 10.26855/er.2021.09.002
\end{abstract}

Received: August 4, 2021

Accepted: August 30, 2021

Published: September 17, 2021

Corresponding author: Angela Magnanini, Department of Sport, Health and Human Sciences, University of Rome ForoItalico, Rome, Italy.

Email: angela.magnanininiroma4.it

\begin{abstract}
The process of inclusion in the paralympic movement is examined from an inclusive pedagogical perspective. At least 100 million disabled people live in Europe alone. A useful definition of the inclusion process is the idea that everyone should be able to use the same facilities, take part in the same activities, and enjoy the same experiences, including people with disabilities or other disadvantages. Inclusion moves in multiple directions involving all people and every aspect of the human condition. Thanks to the great media exposure given to the London Paralympic Games of 2012, the mainstream public came face to face for the first time with athletes with disabilities. This review explores the literature to determine whether inclusion is a regular feature of the paralympic movement, and how it is applied to this specific population; some suggestions for future research in this field will also be provided. The review covered all available research relating to paralympic athletes with special attention to the bio-psycho-social approach, according to the International Classification of Functioning, Disability and Health. This document modifies the concept of health and disability, highlighting the role of context in the process of the individual life. A context that is fraught with barriers places the individual at a disadvantage, while one that is rich in facilitations will help the individual to function in relation to his or her duties and goals, and to participate fully in the social life. The review excludes research projects with a purely medical or clinical approach or with a focus only on performance in paralympic sports. The databases used for the research are Science Direct, Web of Science, ERIC, BASE, DOAJ and they were searched from 2010 until the end of 2021. Rayyan was used to manage the studies. Two independent reviewers screened the records and retrieved 57 articles. The studies included used mixed methods to explore inclusion: on the one hand, they photographed the current situation with questionnaires, surveys or focus groups and, on the other hand, they evaluated inclusive programs, especially with school-age populations. A total of 10,387 participants were involved in the studies included in this review, with a mean of 182.2 and SD of 381.7. Studies suggest that paralympic sports are an excellent tool for inclusion. This review suggests the need to examine the subject more in depth, with experimental studies aimed at investigating inclusion in paralympic sports at the national and international level.
\end{abstract}

\section{Keywords}

Inclusion, paralympic, sport, disability, special pedagogy 


\section{Introduction ${ }^{1}$}

The introduction to this paper will focus on some highlights of the concepts addressed in the review, especially how inclusion is understood in modern documents.

The first part analyses the relationship between disability and inclusion, providing some statistical data. We will examine how the definition of disability is far from finding its own internalisation, especially in the European context, where it relies heavily on the UNCRPD. Inclusion is formally recognized, but also applied in a sectoral way to the different contexts that people with disabilities face.

In the central and final part, we will discuss the concept of inclusion in sports, a process borrowed from the school context that aims to ensure full participation. Its significance in the sports context has followed the more general one related to its evolution in the social context and the passage of the three stages of segregation, integration and inclusion.

\section{Disability and Inclusion}

The ICF and the United Nations Convention on the Rights of Persons with Disabilities (UNCRPD), enacted in 2006, adopted a very broad definition of disability:

'Persons with disabilities include those who have long-term physical, mental, intellectual or sensory impairments which in interaction with various barriers may hinder their full and effective participation in society on an equal basis with others' (Article 1). International policies concerning disability differ widely, but thanks to the Convention and 2030 Agenda promulgated by the U.N., efforts are being made to encourage commitment everywhere to equal rights and shared practices of inclusiveness, focused on the need to educate the public to the importance of inclusion for all people.

According to the World Report on Disability of 2011, “about 15\% of the world's population lives with some form of disability, with about 2-4\% experiencing significant difficulties in functioning. This global estimate of disability is on the rise due to population ageing and the rapid spread of chronic diseases, as well as improvements in the methods used to measure disability. People with disabilities generally have poorer health, lower educational achievements, fewer economic opportunities and higher rates of poverty than people without disabilities. This is largely due to the lack of services available to them and the many obstacles they face in their everyday lives" ${ }^{2}$.

At least 87 million disabled people live in Europe alone ${ }^{3}$, but the European institutions have not created their own definition of disability. They rely heavily on the UNCRPD and the legislation of the individual national states. The latter oscillate between a medical or social approach to disability ${ }^{4}$. When it comes to defining disability, therefore, some Member States adopt an entirely social approach, some a mixed social and medical approach, and others focus primarily or entirely on the medical aspect of disability ${ }^{5}$. Few European Member States have any general legal framework for the definition of disability.

In some member states, the definition of disability differs in relation to the context of application. There are, for example, several definitions for social and professional disability, educational inclusion, compensatory aid or situations of fragility. To prevent misidentification of disability among member states, the EU adopted the United Nations Convention on the Rights of Persons with Disabilities at the end of 2010. Although it has not made this definition mandatory in the national regulatory systems, the EU has verified that the member states comply with the predominant idea.

Participation in cultural life, recreation, leisure and sports is guaranteed by the 30th article of the Convention on the Rights of Persons with Disabilities, that says:

"With a view to enabling persons with disabilities to participate on an equal basis with others in recreational, leisure and sports activities, Member States shall take appropriate measures:

a) To encourage and promote the participation, to the fullest extent possible, of persons with disabilities in mainstream sports activities at all levels;

b) To ensure that persons with disabilities have an opportunity to organise, develop and participate in disability-specific sports and recreational activities and, to this end, encourage the provision, on an equal basis with others, of appropriate instruction, training and resources;

\footnotetext{
${ }^{1}$ Both authors developed the text jointly, specifically: paragraphs 1, 2, 3, 9 are written by Angela Magnanini; 4, 5, 6, 7, 8 by Giulio Morelli ${ }^{2}$ World Health Organization and The World Bank (2011). Summary World report on disability, WHO Press, Geneve.

${ }^{3}$ European Commission - Speech (2021). Opening remarks by Commissioner Dalli on the Strategy for the Rights of Persons with Disabilities 2021-2030. European Commision, Brusselles.

${ }^{4}$ European Parliamanentary Research Service (Marie Lecerf), (2017), European disability policy - From defining disability to adopting a strategy, European Union, Bruxelles.

${ }^{5}$ Social security and social integration, European Commission, (2004) Definition of Disability in Europe: A Comparative Analysis, Brunel University.
} 
c) To ensure that persons with disabilities have access to sports, recreational and tourism venues;

d) To ensure that children with disabilities have equal access with other children to participation in play, recreation and leisure and sports activities, including those activities in the school system;

e) To ensure that persons with disabilities have access to the services provided by those involved in the organisation of recreational, tourism, leisure and sports activities.

Sports are thus fully recognised as a fundamental right for people with disabilities around the world. However, participation and access to sports has not always been guaranteed for fragile individuals. In this context, it becomes crucial to apply the process of inclusion.

The inclusion process has developed over the years to prevent the marginalisation of the most fragile individuals in society. From its first conception until today, inclusive practices are present in different sectors of our daily life, widening more and more the circle of recipients. It is a multi-directional process whose goal is to ensure access and participation. As for the definition of inclusion, two definitions can be used.

The first seeks to focus on inclusion as a means of physical or cultural access to the external reality of any person.

The second insists on the needs and coexistence of individuals with different needs. "Inclusion is a process that aims to respond to the needs of social diversity, teaching people how to live with differently-abled individuals" (Aiscon \& Miles, 2008).

In international legislation, The Convention on the Rights of Persons with Disabilities is an absolute reference document for inclusion. "States adhering to the present Convention recognise the equal right of all persons with disabilities to live in the community, with choices equal to others, and shall take effective and appropriate measures to facilitate full enjoyment by persons with disabilities of this right and their full inclusion and participation in the community, also by ensuring that:

a) b) Persons with disabilities have access to a range of in-home, residential and other community support services, including personal assistance necessary to support living and inclusion in the community, and to prevent isolation or segregation from the community;

b) Community services and facilities for the general population are available on an equal basis to persons with disabilities and are responsive to their needs."

However, it is not enough to focus only on these definitions. Through the review, we can enrich and give a broader and more precise meaning to the inclusion process in Paralympic sports.

\section{Sports inclusion: from school to court}

Inclusion in school was one of the first inclusive practices implemented, especially in the Italian context. This practice was not intended merely to facilitate the coexistence between the able-bodied student and the student with disabilities, but rather to foster real knowledge and interaction among the whole school population.

"Inclusive education must therefore be understood as the process aimed at guaranteeing the right to education for all, regardless of the diversity of each one that may derive from conditions of disability and/or psycho-physical, socio-economic and cultural disadvantage” (Magnanini, 2018).

Inclusion applies to any time in the lives of people with or without disabilities. The concept of inclusion does not stop at school, but broadens its horizons to all the activities that the individual encounters in his or her life. Recently, the processes of inclusion have expanded to other areas of life for people with disabilities, such as work, cultural activities, leisure and sports (Kiuppis, 2016). Inclusion in sports is a particular but always current application of the broader concept of inclusion.

In sports, as well as at school, we have seen a dual link with this practice. The sports environment can be both a place where inclusion is applied, and a place where inclusion can be taught. The values and dynamics of the gym adapt very easily to this practice. In addition, the encounter-clash with a group of peers manages to make the athlete with disabilities feel at the centre of a positive path, a safe and healthy environment.

"The link, therefore, between school inclusion and social inclusion becomes fundamental and, in this direction, a possible link can be represented by sports, whose inclusive practice within the school system in full continuity with the extra-curricular life can have positive effects on the social inclusion system” (Magnanini, 2018).

However, simply letting people play together is not enough to ensure the formation of a positive context for the person with disabilities. This concept applies to any sports activity, whether it be Olympic or Paralympic. The sports context has particular characteristics that must be put into practice regardless of the inclusive intent of the discipline. In this context, the Paralympic movement plays a decisive role in the success of inclusion in sports.

In addition, at the international level it is not easy to find an unambiguous definition of the inclusion process because it is a new and developing world. The development of sports for people with disabilities has followed the development 
of the concept of disability (see Table 1 and Table 2). There has been a shift from a tendency toward separation, in which the athlete with a disability could only play with his peers, to a movement in favour of integration, where the disabled could play with the able-bodied but with special rules, and then arrive at a truly inclusive context, in which the rules applied to all players without distinction of disability.

Table 1. Evolution of sports for people with disabilities through time, the changes were possible because of a different social approach to people with disabilities (Magnanini, 2018a; Moliterni, 2013)

\begin{tabular}{ccc}
\hline Special Sport & Adapted Sport & Integrated Sport \\
\hline
\end{tabular}

This sport is designed in rules, in spaces and equipment exclusively for certain types of disabilities (e.g. Torball for the blind)
Existing sport adapts to impairments of specific groups specific groups of people with disabilities.

(e.g. wheelchair basketball)
A sport is designed in the rules, spaces and equipment to enable people to participate together and in an active way, with and without disabilities by enhancing the skills and potential of everyone. (e.g. Baskin)

Separation

Separation

Inclusion

Table 2. Evolution of sports for people with disabilities through time, the changes were possible because of a different social approach to people with disabilities (Magnanini, 2018; Magnanini, 2018a; Moliterni, 2013)

Unified Sport

Mixed Ability Sport

Integrated Sport

These are sports with rules very similar to those of sports federations in which people with and without intellectual disability, of similar age and similar abilities (in the case of the "competitive model"), play together on the same team.

People with intellectual disabilities are called "athletes" while those without disabilities are called "partners".
These are sports in which people with and without disabilities play together. They follow the same rules as traditional sports, allowing minimal adjustments to take into account the specific needs of the participants.
These are sports designed from the ground up for inclusive purposes, modifying rules, spaces and equipment, so that people with and without disabilities can participate together in an active way, enhancing the skills and potential of each through specific roles.

The evolution of a more inclusive approach to sports must necessarily take into account the community of the Paralympic movement, which today manages and organizes not only the Paralympic Games but also all local and national championships. For this reason, inclusion must be studied within Paralympic sports, to clarify this issue.

\section{The Paralympic movement}

The history of the paralympic movement is fundamental to understanding the evolution of the inclusion process. As mentioned above, its evolution has been influenced by profound changes within society.

The first attempt to recreate sport for persons with disabilities was in 1888 in Berlin. However, it was not until the Second World War that it began spreading worldwide. Dr. Ludwig Guttman, who directed a spinal cord injuries centre, experimented a new type of rehabilitation based on sports. On the same day as the London Olympic Games, 29 July 1948, he inaugurated the first Stoke Mandeville Games, a prototype of Paralympic Games for wheelchair athletes. Later, the Stoke Mandeville Games became the Paralympic Games of Rome in 1960, with 400 athletes from 23 countries $^{6}$.

After the great media exposure provided by the London Paralympic Games of 2012, the mainstream public was confronted for the first time with athletes with disabilities. Nowadays, the movement is growing at a very interesting rate in terms of participation in the Paralympic Games. More and more persons with disabilities and countries play together in a variety of sports designed for inclusion and competition as well. 4,328 athletes from 160 countries participated in the Rio Paralympic Games of 2016 with the following disabilities included: Spinal injury, Amputee, Vision Impairment, Cerebral Palsy, Les Autres, and Intellectual Disability. This increased the demands that Paralympics organizing states and national Paralympics managers face.

Nowadays, the International Paralympic Committee is a well-structured body. The IPC manages the Paralympic

${ }^{6}$ International Paralympic Committee, History of the Paralympic Movement. https://www.paralympic.org/ipc/history 
Games, while its territorial branches organise national and local championships. The structure follows the successful one within the Olympic Committee with independent National Paralympic Committees and other private or public organisations that cooperate in the name of sports. The IPC guarantees respect of the rules, the classifications (that determine the type and degree of disability) and the continuity of games and championships.

\section{Aim}

In accordance with the general framework outlined above, inclusion in the Paralympic movement is a fundamental value, not yet fully studied. Previous reviews have focused mainly on the medical, rehabilitation and performance dimensions, neglecting the social aspects and implications of adapted physical and sports activity.

The aim of this review is to categorise research at an international level, with a bio-psycho-social approach, to systematise the literature on inclusion in the Paralympic movement. Furthermore, this review aims to define the inclusion process more clearly.

\section{Methods}

\subsection{Protocol}

The authors followed the reporting guidelines of the PRISMA 2020 Protocol. The final review will be reported following the PRISMA statement.

\subsection{Eligibility criteria}

The authors included any research related to Paralympic athletes with special attention to the bio-psycho-social sphere. They excluded research with a purely medical or clinical approach or with a focus only on performance in Paralympic sports. They also excluded studies with fewer than 10 participants. Studies were excluded by the following criteria:

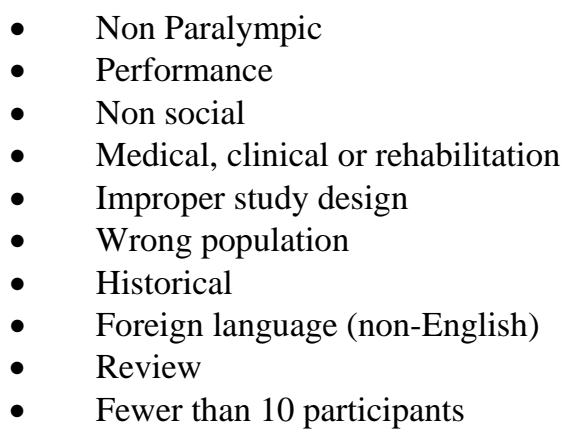

\subsection{Type of participants}

The participants are Paralympic athletes, people with disabilities who practice sports for both competitive and recreational purposes. The review included people with intellectual disabilities, physical impairments and able-bodied people who play Paralympic sports; it ruled out people with chronic diseases such as diabetes, strokes, heart attacks or cancer who play non-agonistic sports.

\subsection{Types of outcome measured and intervention}

The authors will analyse the results with a qualitative-quantitative approach to highlight evidence of inclusion in the Paralympic movement and the consequent cultural and social impact in the reference context. A narrative synthesis of all studies will be presented by type of outcome (inclusion, experiences, barriers and facilitators) and type of intervention.

\subsection{Information sources and search strategy}

Science Direct, Web of Science, ERIC, BASE, DOAJ were searched from 2010 until the end of 2021. The authors excluded non-English references. The keywords used in this database are described in file 1 . The reference list of the studies included in this review was searched to manually include potentially important studies. 


\subsection{Selection process}

Rayyan was used to manage the studies. The software automatically identifies duplicates and removes them. Two independent reviewers screened the records and retrieved 57 articles. The "PRISMA 2020 flow diagram for new systematic reviews which included searches of databases, registers and other sources” will be used.

\subsection{Data extraction}

The reviewers will extract the following information:

- Title, authors and year of publication

- Sports context (Paralympic, non-agonistic, physical education or recreational sports)

- Participants (with or without disabilities, demographic information, employment)

- Research methods

- Outcomes

- Results

- $\quad$ Limits of the research

\subsection{Study risk of bias (quality) assessment}

Two independent reviewers check and include studies. Every disagreement is confronted and resolved.

\subsection{Synthesis methods}

The data will be analysed through a qualitative-quantitative analysis of the databases using the Rayyan software. Data will be organised in thematic cores and there will be a narrative analysis of inclusion in the international literature from the years 2010 to 2021. Voyant Tools will be used to search the correlation between words and to find a new definition of inclusion process.

\subsection{Dissemination}

The findings of the review will be disseminated in a related peer-reviewed journal and they will also contribute to a PhD thesis.

\section{Results}

\subsection{Study selection}

The PRISMA 202 Flow Diagram was used to visually summarise the studies on the process of inclusion or exclusion (file 2). The review starts from 9,683 documents and covers 57 studies.

\subsection{Results of individual studies: Study characteristics}

The research focused on two modalities: photographing the current situation through questionnaires, focus groups or mixed qualitative-quantitative methods or evaluating the effects of a Paralympic sports program experience. The research was carried out in different contexts such as schools, the Paralympic gym or on the internet to extend them to the public. The studies investigate a heterogeneous population composed of students of different grades, Paralympic and non-Paralympic athletes, parents of children with disabilities as well as able-bodied adults.

A total of 10,387 participants were involved in the studies included in this review, with a mean of 182.2 and SD of 381.7.

From the analysis of the sports context (see Figure 1), it can be seen that most of the research is focused on competitive and school sports. The participants are, contrary to expectations, for the most part people without disabilities and only in second place people with disabilities (see Figure 2). The studies regarding people with and without disabilities are few.

The research methods (see Figure 3) were both qualitative and quantitative. Semi-structured interviews and questionnaires or surveys were largely used.

\subsection{Thematic Analysis}

The thematic analysis (see Figure 4) of word occurrences was performed using the Voyant Tools software. Both the number of times a word was repeated and the term with which it was most often associated were analysed. 


\section{Sports context}

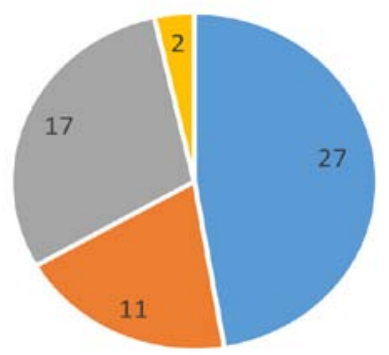

- Grassroots sport = Paralympic

= Physical education = Recreational sport

Figure 1. Sport context.

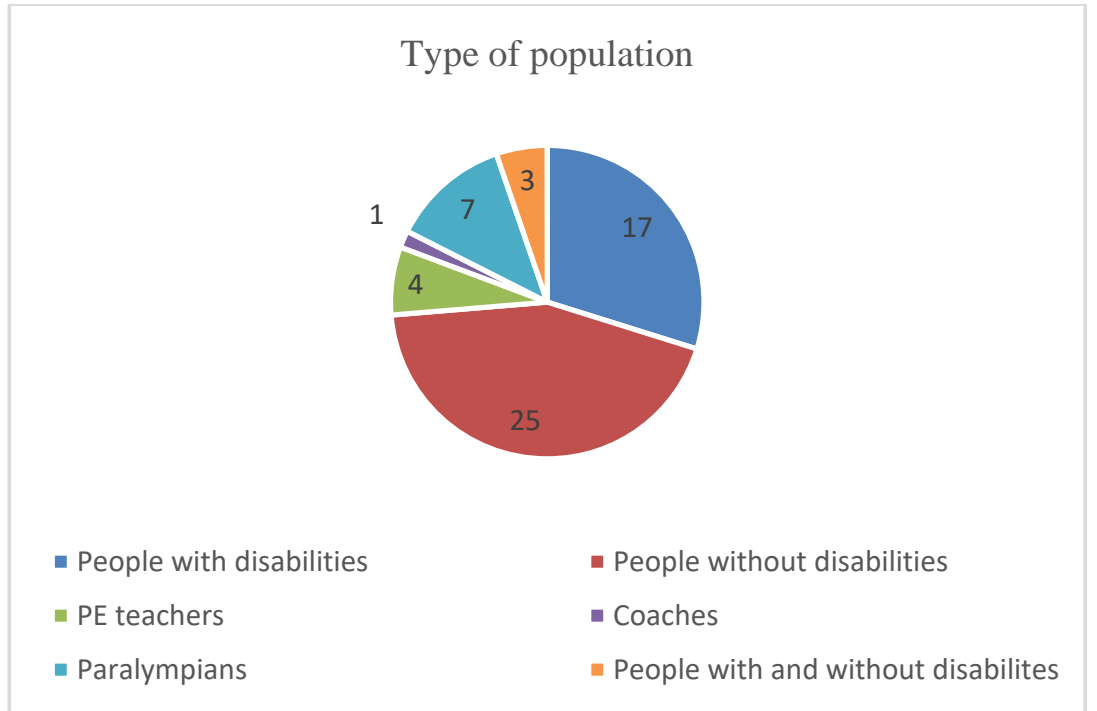

Figure 2. Population.

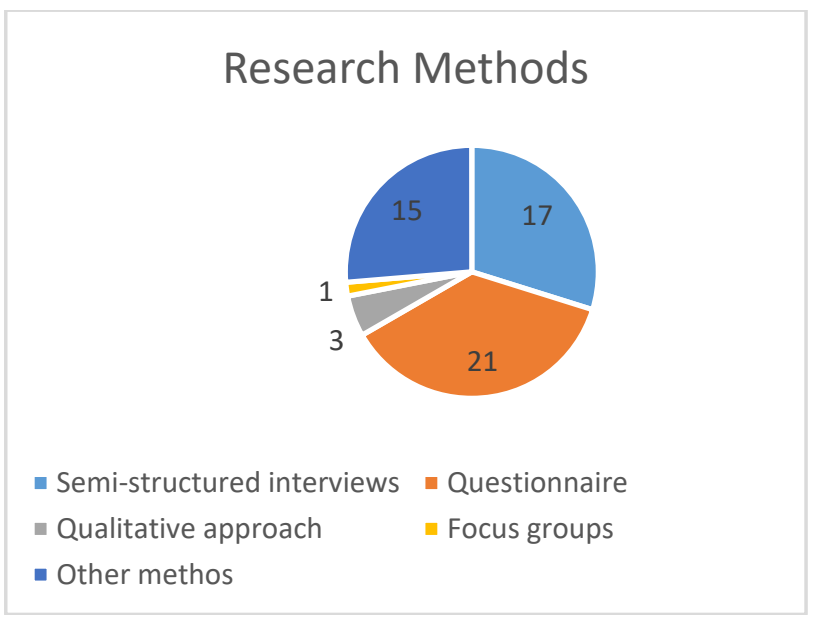

Figure 3. Research Methods. 


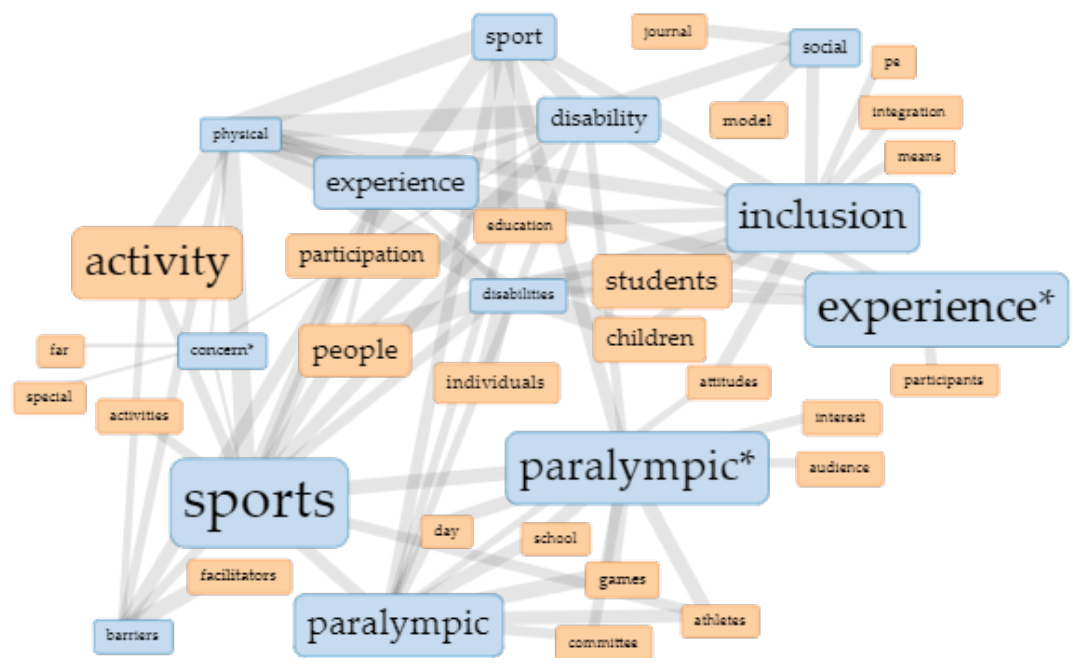

Figure 4. The picture was created by Voyant Tools (The words* with the asterisk indicate similar words).

Inclusion is a social process that can be taught, using appropriate educational means, with the goal of ensuring, as much as possible, access to social contexts for people with disabilities or any kind of physical, intellectual or social deficit. Its success is strongly linked to the attitudes of the target group and of the person to be included, and sports can be a primary integration tool in educational settings for students and children during physical education classes. Many initiatives, which we will explore in detail later, have been organized precisely in school settings. In these contexts, inclusive processes are posed as a means of bringing together people with and without disabilities.

Sports and the Paralympic movement are in close synergy. Thanks to the organisation of federative and confederative bodies, it is possible to play at the local, national and international level with a group of peers. In particular, the Paralympic Games are an exceptional opportunity for people with disabilities. Thanks to the Games moment, they can have not only a great personal experience, but also great media exposure which brings them to the attention of the mainstream public. This participation is one of the main keys to inclusion, though it can be severely hindered by physical or cultural barriers. Facilitators can mitigate these barriers and ensure full accessibility.

Education is the junction between inclusion, sports and paralympic engagement. In the various studies, we will examine hereafter, the authors want to create a change in the participant's mentality through education, formal or informal. For example, the programs were designed to spread the values of inclusion through paralympic sports in different forms. Some activities were hands-on, others used an indirect form, such as viewing audio-visual productions. At the beginning and end of the program, the authors carried out an evaluation that demonstrates the positive effects; people changed their attitudes or opinions towards people with disabilities. Involvement in hands-on activities such as sports and physical education proved to be very effective in spreading inclusive values. Therefore, inclusion is a dynamic process, rather than a static one. It is not enough to formalise an inclusive process to make it happen, because only confrontation with others can ensure the development of awareness about disability.

Experience is another important element that stands between sports and disability. In research, it is meant both as the present moment in which a life experience is proposed through Olympic sports and as previous experience. In the educational programs mentioned above, it acquires the significance of a teaching moment. It is also seen as past life experience, when inclusion (or exclusion) was experienced. In both cases, it takes on an important meaning for the person; the background of experience is decisive for the creation of an inclusive path.

Disability is surrounded by many areas of interest. In this context, the social aspect is very important for a person's well-being and Paralympic sports can be one of the most suitable tools to satisfy not only the need for socialisation but also needs related to the physical sphere. One of the greatest dangers for people with disabilities, which emerges often in other reviews, is that of isolation. If prolonged over time, isolation can trigger a negative spiral, even from health perspective. Sports, on the other hand, not only allow people to experience social life in a positive way, but also enable them to meet their peers in ways that would otherwise be impossible. Often disabled individuals suffer from not being able to compare themselves with people who have the same disability. Paralympic sports make these encounters possible.

The person with a disability also has to deal with concerns often related to the specificity of his or her needs and the distance of the proposed activities. Physical disability is the one most analysed in the research included in the review. 
To summarise and provide a definition from the relevant literature, inclusive processes allow normal access to people with physical, intellectual or social disabilities. Inclusion is influenced by individuals' attitudes, participation, barriers/facilitators, past and present experiences and concerns.of affiliation 1. Repeat as necessary for each additional affiliation.

\section{Discussion}

A thematic analysis of the results was conducted to analyse the most significant conclusions of the studies examined.

Paralympic sports improve the well-being, quality of life and social inclusion of people with disabilities (Válková, Hansgut, \& Nováčková, 2010; Shapiro \& Martin, 2010; Wadey \& Day, 2018; Sansi et al., 2020; Lee, 2020; Kamberidou, Bonias, \& Patsantaras, 2019; Fokolade, Latimer-Cheung, \& Shirazipour, 2021; Ciampolini et al., 2018; Frumberg et al., 2019; Tindall, Foley, \& Lieberman, 2016; Conroy, 2015; Grenier et al., 2014), even if the type of disability is still decisive for the success of inclusive practices within sports contexts (Darcy, 2017). It also favours the construction of an athletic identity in the target population (Piatt, 2018).

Numerous studies suggest that Paralympic sports directly or indirectly favour an improvement in attitudes towards disabilities and disabled athletes, even when simply seen on television (Bebetsos et al., 2014; Weissman et al., 2019; Richardson, Smith, \& Papathomas, 2017a; Richardson, Smith, \& Papathomas, 2017b; McKay et al., 2015; McKay et al., 2019; McKay et al., 2020; McKay et al., 2021; Reina et al., 2019; Reina et al., 2020; Perez-Torralba et al., 2019; Bartsch et al., 2018; Dalbudak \& Yigit, 2019; Souza, Marques, \& Fermino, 2020; Pullen, Jackson, \& Silk, 2021; Jesina, Kudláček, \& Liu, 2010; Kudláček, Evaggelinou, \& Doulkeridou, 2010; Haishima et al., 2020; Stone, 2021; Ferrara, 2018).

A line of research has studied training and education, and has found little information on the topic of the inclusion of Paralympic technical personnel (Wareham et al., 2018); the quality of Paralympic activity is based on the professional preparation of the technical personnel (Patatas et al., 2016).

Although inclusion is recognized as a complex phenomenon involving many different aspects, such as positive attitude, support, modification, peer tutoring, and additional in-service training (Sang Soo Park, 2014), much research suggests that barriers and facilitators are the main elements affecting to access to Paralympic sports (McLoughlin et al., 2017; Charles \& Chinaza, 2018). Barriers may be purely physical (Carrol, 2020; Lape et al., 2018; Wang, 2019), or cultural, such as the lack of knowledge of disability (RaufAbbassi, Farhan, \& Hussain, 2020), or merely athletic, for example low frequency of training (Nettleton et al., 2017). As regards facilitators, it is found that enjoyment and the social context (Jaarsma et al., 2014; Richardson, Smith, \& Papathomas, 2017; Richardson, Smith, \& Papathomas, 2017; Goodwin et al., 2011), correct communication of the proposed activities (Jaarsma, Haslett, \& Smith, 2019) and awareness of Paralympic sports (Reina et al., 2019; Columna et al., 2018), all contribute to increase participation and involvement in the proposed activities.

There are a few studies that suggest that Paralympic sports do not promote inclusion (Haegele et al., 2020) or do not have a significant impact on well-being or quality of life (Bolach \& Prystupa, 2014). One study even reported that Paralympic sports do not improve attitudes towards disability (Ogu, Umunnah, \& Nwosu, 2016). Finally, there is also a study that finds that Paralympic athletes may still experience moments of exclusion and low self-esteem (Swartz et al., 2018), as do students with disabilities in physical education classes (Qi \& Wang, 2018; Sanches-Ferreira et al., 2019).

\section{Conclusion}

Numerous studies and reviews have dealt with the medical, clinical or performance-related aspects of disability and Paralympic sports; the very rare existing reviews on inclusion in Paralympics are sport-specific or context-specific, related to a nation or exclusively to schools. In this review, the approach was purely social and aimed at investigating inclusion in Paralympic sports as a whole.

This review suggests that Paralympic sports are a tool for inclusion. Their realization is often complex but not complicated. Considerable medical knowledge is required of the technical personnel and organisers of Paralympic sports activities, in addition to knowledge and skill in the particular sports involved, but this is increasing rapidly, driven by the success of the Paralympics themselves.

Inclusion is a real factor, constantly practiced in Paralympic sports. It is also a concept in continuous evolution by its very nature, as it is never fixed, but continuously adapted to individuals and groups. Its most important components are certainly the attitudes towards disability both of the person involved and of all the external subjects. The reduction of barriers and the creation of facilitators is decisive for its success and must be prepared in advance of the intervention. The required training must not be simply notional, but must dive into the dynamics of individual disabilities and be sport-specific. Participation, past and present experience and concerns play a decisive role in the inclusion process. 
However, it should be noted that inclusion in Paralympic sports is not automatic, so those who participate will not necessarily feel included, or stable over time, as factors internal or external to the individual can change, in both positive and negative ways.

This review suggests the need to deepen the subject with experimental studies aimed at investigating the dimensions of inclusion in Paralympic sports at the national and international level.

\section{References}

Ainscow, M. and Miles, S. (2008). Making Education for All inclusive: where next? Prospects, 38/1, 15-34

Bartsch, A., Oliver, M., Nitsch, C., Scherr, S., Bartsch, A., Oliver, M. B., Nitsch, C., and Scherr, S. (2018). Inspired by the Paralympics: Effects of Empathy on Audience Interest in Para-Sports and on the Destigmatization of Persons With Disabilities. COMMUNICATION RESEARCH, 45(4), 525-553.

Bebetsos, E., Derri, V., Filippou, F., Zetou, E., and Vernadakis, N. (2014). Elementary School Children's Behavior towards the Inclusion of Peers with Disabilities, in Mainstream Physical Education Classes. ERPA International Congress on Education, ERPA Congress 2014, 6-8 June 2014, Istanbul, Turkey, 152, 819-823.

Bolach, B. and Prystupa, T. (2014). Evaluation of perception of quality of life of disabled athletes. Physical education of students. 2014, 18(1): 13-6.

Carroll, P., Witten, K., and Duff, C. (2020). “How can we make it work for you?” Enabling sporting assemblages for disabled young people. Social Science \& Medicine, 113213.

Charles, O. O. and Chinaza, N. K. (2018). Barriers and Facilitators of Physical Activity Participation Among Youth with Visual and Hearing Impairments in Nigeria: A Qualitative Study. Palaestra, 32(3), 21-27.

Ciampolini, V., Pinto, M. G., Sousa, G. R. de, Silva, D. A. S., and Galatti, L. R. (2018). Do athletes with physical disabilities perceive their quality of life similarly when involved in different Paralympic Sports? In Motriz. The Journal of Physical Education, 24, 4, 1-6.

Columna, L., Streete, D. A., Hodge, S. R., Dillon, S. R., Myers, B., Norris, M. L., Barreira, T. V., and Heffernan, K. S. (2018). Parents’ Beliefs About Physical Activity for Their Children With Visual Impairments. Adapted Physical Activity Quarterly, 35(4), 361-380.

Conroy, P. (2015). Investigation of the impact of recreational ski program on children who are blind and visually disabled. Palaestra, 29(4), 36-39.

D’Alonzo L. (2019a). Special Pedagogy for inclusion. Brescia: Scholè (original text in Italian: Pedagogia speciale per l'inclusione).

D’Alonzo L. (2019b). Dictionary of Special Pedagogy, edited by Brescia, Scholè (original text in Italian: Dizionario di Pedagogia speciale).

Dalbudak, I. and Yigit, S. (2019). Hearing Imparied Students' Attitudes towards Physical Education and Sports. Journal of Education and Training Studies, 7(9), 55-60.

Darcy, S., Lock, D., and Taylor, T. (2017). Enabling Inclusive Sport Participation: Effects of Disability and Support Needs on Constraints to Sport Participation. Leisure Sciences, 39(1), 20-41.

Fakolade, A. O., Latimer-Cheung, A. E., and Shirazipour, C. H. (2021). Quality participation: Perspectives of physical activity service providers for veterans with disabilities. Disability and Health Journal, 101094.

Ferrara, K., Burns, J., and Mills, H. (2015). Public Attitudes Toward People With Intellectual Disabilities After Viewing Olympic or Paralympic Performance. Adapted Physical Activity Quarterly, 32(1), 19-33.

Florian Kiuppis. (2018). Inclusion in sport: disability and participation. Sport in Society, 21: 1, 4-21. DOI: 10.1080/17430437.2016.1225882.

Frumberg, D., Gerk, A., Autruong, P., Flynn, K., Pan, Z., and Chang, F. (2019). Adaptive Skiing/Snowboarding Affects the Quality of Life of Children With Disabilities. Palaestra, 33(3), 21-26.

Goodwin, D. L., Lieberman, L. J., Johnston, K., and Leo, J. (2011). Connecting Through Summer Camp: Youth With Visual Impairments Find a Sense of Community. Adapted Physical Activity Quarterly, 28(1), 40-55.

Grenier, M., Collins, K., Wright, S., and Kearns, C. (2014). Perceptions of a Disability Sport Unit in General Physical Education. Adapted Physical Activity Quarterly, 31(1), 49-66.

Haegele, J., Hodge, S., Zhu, X., Holland, S., Wilson, W., Haegele, J. A., Hodge, S. R., Zhu, X., Holland, S. K., and Wilson, W. J. (2020). Understanding the Inclusiveness of Integrated Physical Education From the Perspectives of Adults With Visual Impairments. Adapted Physical Activity Quarterly, 37(2), 141-159.

Haishima, M., Kajita, N., Aoki, K., and Kato, C. (2020). A Survey on People’s Impressions of the Paralympic Games. Open Journal of Social Sciences, 8, 436-444. 
Jaarsma, E. A., Dekker, R., Koopmans, S. A., Dijkstra, P. U., and B. Geertzen, J. H. (2014). Barriers to and Facilitators of Sports Participation in People With Visual Impairments. Adapted Physical Activity Quarterly, 31(3), 240-264.

Jaarsma, E. A., Haslett, D., and Smith, B. (2019). Improving Communication of Information About Physical Activity Opportunities for People With Disabilities. Adapted Physical Activity Quarterly, 36(2), 185-201.

Ješina, O., Kudláček, M., and Liu, Y. (2010). The influence of Paralympic School Day on children’s attitudes towards people with disabilities. Acta Univ. Palacki. Olomuc., Gymn. 2010, 40, 2, 63-69.

Kamberidou, I., Bonias, A., and Patsantaras, N. (2019). Sport as a means of inclusion and integration for "those of us with disabilities”. European Journal of Physical Education and Sport Science, 5, 12, 99-128.

Kudláček, M., Evaggelinou, C., and Doulkeridou, A. (2010). Components of attitudes toward the inclusion of students with disabilities in physical education in the ATIPDPE-GR instrument for Greek physical educators, Acta Univ. Palacki. Olomuc., Gymn., 40, 4, 63-68.

Kurková, P., Válková, H., and Scheetz, N. (2011). Factors impacting participation of European elite deaf athletes in sport. Journal of Sports Sciences, 29(6), 607-618.

Lape, E. C., Katz, J. N., Losina, E., Kerman, H. M., Gedman, M. A., and Blauwet, C. A. (2018). Participant-Reported Benefits of Involvement in an Adaptive Sports Program: A Qualitative Study. PM\&R, 10(5), 507-515.

Lee, K., Narasaki-Jara, M., Park, J., Lai, B., Davis, R., Oh, J., Lee, K., Narasaki-Jara, M., Park, J., Lai, B., Davis, R., and Oh, J. (s.d.). The Long-term Effect of a Paralympic Sports Class on Korean High School Students' Attitudes towards Peers with Disabilities and Perceptions of Their Human Rights. International journal of disability development and education. International Journal of Disability, Development and Education.

Magnanini A., et al. (2018b). Integrated sport. Keywords of an inclusive model, Proceeding book. 3rd International Eurasian Conference on Sport Education and Society. International Science, Culture and Sport Association.

Magnanini, A. (2021). Accessibility \& education, in L. Bellatalla, E. Marescotti., Between science and the history of education. Roma: Anicia. (original text in Italian: Accessibilità ed educazione).

Magnanini. (2018a). Special education and sport. Models, activities and inclusive contexts between school and extracurricular activities. Incontropiede Publishing: Padova. (original text in Italian: Pedagogia speciale e sport. Modelli, attività e contesti inclusivi tra scuola ed extrascuola).

McKay, C., Block, M., Park, J., McKay, C., Block, M., and Park, J. Y. (2015). The Impact of Paralympic School Day on Student Attitudes Toward Inclusion in Physical Education. Adapted Physical Activity Quarterly, 32(4), 331-348.

McKay, C., Haegele, J., Block, M., McKay, C., Haegele, J., and Block, M. (2019). Lessons learned from Paralympic School Day: Reflections from the students. EUROPEAN PHYSICAL EDUCATION REVIEW, 25(3), 745-760.

McKay, C., Haegele, J., McMahon, J., McKay, C., Haegele, J., and McMahon, J. (2020). Utilizing Documentary Film as a Pedagogical Methodology: Exploring the Student Experience Through Writing to Learn After Viewing The Rebound: A Wheelchair Basketball Story. PHYSICAL EDUCATOR-US, 77(2), 271-293.

McKay, C., Park, J., Block, M., McKay, C., Park, J. Y., and Block, M. (2021). Exploring the variables associated with student attitudes toward inclusion in physical education after taking part in the Paralympic School Day programme. International Journal of Inclusive Education, 25(3), 329-347.

McKay, C., Walters, J., Haegele, J., McKay, C., Walters, J., and Haegele, J. (2019). The Impact of a Disability Sport Documentary: Depicting the College Student Viewing Experience through Reflective Essays. PALAESTRA, 33(4), 27-32.

McLoughlin, G., Weisman Fecske, C., Castaneda, Y., Gwin, C., and Graber, K. (2017). Sport Participation for Elite Athletes With Physical Disabilities: Motivations, Barriers, and Facilitators. AdaptedPhysical Activity Quarterly, 34(4), 421-441.

Moliterni, P. (2013). Didactics and motor science. Roma: Armando (original text in Italian: Didattica e scienza motorie).

Nettleton, L., Hassett, L., Scheibe, F., Price, R., Kirkham, C., and Sherrington, C. (2017). Sport and Physical Activity Participation Among People With Disabilities Reported at a Sports Exhibition and Six Months Later. Therapeutic Recreation Journal, 51(3), 206-220.

Ogu, O. C., Umunnah, J. O., and Nwosu, K. C. (2016). Disability types, self-efficacy, and attitude to participate in physical activity in children with disabilities: a pilot study. Palaestra, 30(4), 25-32.

Park, S. S., Koh, Y., and Block, M. (2014). Contributing factors for Successful Inclusive Physical Education. Palaestra, $28(1)$, 42-49.

Patatas, J., Duarte, E., de Almeida, J., Patatas, J. M., Duarte, E., and Gaviao de Almeida, J. J. (2016). The main dilemmas of taekwondo training of students with disabilities-Analysis of the opinion of professional coaches. ARCHIVES OF BUDO, 12. 159-166.

Perez-Torralba, A., Reina, R., Pastor-Vicedo, J., Gonzalez-Villora, S., Perez-Torralba, A., Reina, R., Carlos Pastor-Vicedo, J., and Gonzalez-Villora, S. (2019). Education intervention using para-sports for athletes with high support needs to improve attitudes 
towards students with disabilities in Physical Education. European Journal of Special Needs Education, 34(4), 455-468.

Piatt, J., Kang, S., Wells, M. S., Nagata, S., Hoffman, J., and Taylor, J. (2018). Changing identity through sport: The Paralympic sport club experience among adolescents with mobility impairments. Disability and Health Journal, 11(2), 262-266.

Pullen, E., Jackson, D., and Silk, M. (2021). Paralympic broadcasting and social change: An integrated mixed method approach to understanding the Paralympic audience in the UK. Television \& New Media, 1-21.

Qi, J. and Wang, L. (2018). Social interaction between students with and without disabilities in general physical education: A Chinese perspective. Physical Education \& Sport Pedagogy, 23(6), 575-591.

RaufAbbasi, M. A., Farhan, C. M., and Hussain, F. (2020). Opening new frontiers in adaptive sports for special persons through inclusion. The Spark, 5, 98-125.

Reina, R., Healy, S., Roldán, A., Hemmelmayr, I., and Klavina, A. (2019). Incluye-T: a professional development program to increase the self-efficacy of physical educators towards inclusion. Physical Education \& Sport Pedagogy, 24(4), $319-331$.

Reina, R., Iniguez-Santiago, M. C., Ferriz-Morell, R., Martinez-Galindo, C., Cebrian-Sanchez, M., and Roldan, A. (2021). The effects of modifying contact, duration, and teaching strategies in awareness interventions on attitudes towards inclusion in physical education. European journal of special needs education. Journal of Autism and Developmental Disorders, 51: $2254-2270$.

Reina, Raul, Hutzler, Y., Iniguez-Santiago, M. C., and Moreno-Murcia, J. A. (2019). Student Attitudes Toward Inclusion in Physical Education: The Impact of Ability Beliefs, Gender, and Previous Experiences. Adapted Physical Activity Quarterly, 36(1), 132-149.

Richardson, E. V., Smith, B., and Papathomas, A. (2017a). Collective Stories of Exercise: Making Sense of Gym Experiences With Disabled Peers. Adapted Physical Activity Quarterly, 34(3), 276-294.

Richardson, E. V., Smith, B., and Papathomas, A. (2017b). Crossing boundaries: The perceived impact of disabled fitness instructors in the gym. Psychology of Sport and Exercise, 29, 84-92.

Sanches-Ferreira, M., Alves, S., Silveira-Maia, M., Gomes, M., Santos, B., \& Lopes-dos-Santos, P. (2019). Participation in Leisure Activities as an Indicator of Inclusion: A Comparison between Children with and without Disabilities in Portugal. European Journal of Educational Research, 8(1), 221-233.

Sansi, A., Nalbant, S., Ozer, D., Sansi, A., Nalbant, S., and Ozer, D. (2021). Effects of an Inclusive Physical Activity Program on the Motor Skills, Social Skills and Attitudes of Students with and without Autism Spectrum Disorder. JOURNAL OF AUTISM AND DEVELOPMENTAL DISORDERS, 51, 7, 2254-2270.

Shapiro, D. R. and Martin, J. J. (2010). Athletic identity, affect, and peer relations in youth athletes with physical disabilities. Disability and Health Journal, 3(2), 79-85.

Souza, D. L. de, Marques, A. M., and Fermino, A. L. (2020). Paralympic games: the experience with "the other" through the screens. Journal of Physical Education, v. 31, e3170, 1-9.

Stone, R. C., Sweet, S. N., Perrier, M.-J., MacDonald, T., Martin Ginis, K. A., and Latimer-Cheung, A. E. (2019). Exploring Stereotypes of Athletes With a Disability: A Behaviors From Intergroup Affect and Stereotypes Map Comparison. Adapted Physical Activity Quarterly, 36(3), 339-358.

Swartz, L., Bantjes, J., Knight, B., Wilmot, G., Derman, W., Swartz, L., Bantjes, J., Knight, B., Wilmot, G., and Derman, W. (2018). "They don't understand that we also exist”: South African participants in competitive disability sport and the politics of identity. Disability and rehabilitation, 40(1), 35-41.

Tindall, D., Foley, J., and Lieberman, L. (2016). Incorporating sport education roles for students with visual impairments and blindness as part of a sport camp experience. Palaestra, 30(3), 31-36.

Válková, H., Hansgut, V., and Nováčková, M. (2010). Movement activities in the life-style of Special Olympians (persons with mental disability). WCPCG, 5, 1859-1862.

Wadey, R. and Day, M. (2018). A longitudinal examination of leisure time physical activity following amputation in England. Psychology of Sport and Exercise, 37, 251-261.

Wang, L. (2019). Perspectives of Students With Special Needs on Inclusion in General Physical Education: A Social-Relational Model of Disability. Adapted Physical Activity Quarterly, 36(2), 242-263.

Wareham, Y., Burkett, B., Innes, P., Lovell, G., Wareham, Y., Burkett, B., Innes, P., and Lovell, G. P. (2018). Sport coaches’ education, training and professional development: The perceptions and preferences of coaches of elite athletes with disability in Australia. SPORT IN SOCIETY, 21(12), 2048-2067.

Weissman, S. E., Lithopoulos, A., Tomasone, J. R., and Latimer-Cheung, A. E. (2019). Exploring gaze behaviors toward images of physically active individuals with a physical disability. Psychology of Sport and Exercise, 45, 101533.

WHO. (2001). International Classification of Functioning, Disability and Health. New York: 2001. 